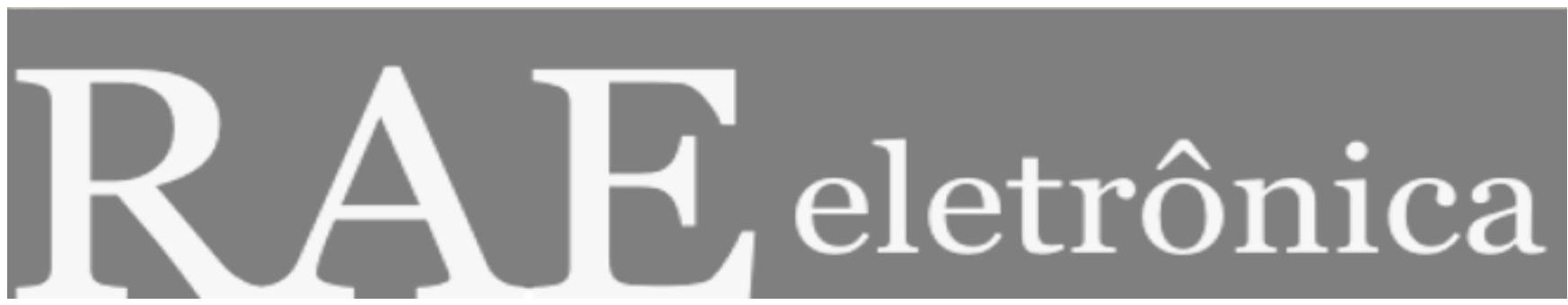

\title{
A POBREZA COMO UM FENÔMENO MULTIDIMENSIONAL
}

Por:

\section{Antônio Pedro Albernaz Crespo \\ Elaine Gurovitz}

RAE-eletrônica, Volume 1, Número 2, jul-dez/2002.

http://www.rae.com.br/eletronica/index.cfm?FuseAction=Artigo $\&$ ID $=1178 \&$ Secao $=$ PÚBLICA $\&$ Volume $=1 \&$ Numero $=2 \&$ $\mathrm{Ano}=2002$

CCopyright, 2002, RAE-eletrônica. Todos os direitos, inclusive de tradução, são reservados. É permitido citar parte de artigos sem autorização prévia desde que seja identificada a fonte. A reprodução total de artigos é proibida. Os artigos só devem ser usados para uso pessoal e nãocomercial. Em caso de dúvidas, consulte a redação: redacao@,rae.com.br.

A RAE-eletrônica é a revista on-line da FGV-EAESP, totalmente aberta e criada com o objetivo de agilizar a veiculação de trabalhos inéditos. Lançada em janeiro de 2002, com perfil acadêmico, é dedicada a professores, pesquisadores e estudantes. Para mais informações consulte o site www.rae.com.br/eletronica.

RAE-eletrônica

ISSN 1676-5648

(C)2002 Editora: Fundação Getulio Vargas - Escola de Administração de Empresas de São Paulo.

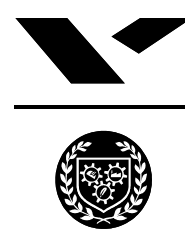

F U N D A C Ã O GETULIO VARGAS

Escola de Administração de Empresas de São Paulo 


\title{
A POBREZA COMO UM FENÔMENO MULTIDIMENSIONAL
}

\author{
Antônio Pedro Albernaz Crespo \\ Mestre em Administração Pública e Governo pela FGV-EAESP. \\ E-mail: apcrespo@gvmail.br \\ Endereço: Rua Voluntário Penna Ramos, 260 - Apt. 11 - Centro - Taubaté - SP, 12010-740 \\ Interesse de Pesquisa: Finanças Públicas e Desenvolvimento Regional.
}

\section{Elaine Gurovitz}

Mestre em Administração Pública e Governo pela FGV-EAESP.

E-mail: egurovitz@yahoo.com.br

Endereço: Rua Herculano, 500/74 - São Paulo - SP, 01257-003.

Interesses de pesquisa: Pobreza em várias dimensões como gênero e raça.

\section{RESUMO}

O presente artigo tem o objetivo de contribuir para a discussão sobre a pobreza. Nesse sentido, descreve-se uma abordagem desse fenômeno cada vez mais utilizada na atualidade: a de privação de capacidades, elaborada por Amartya Sen. Tal abordagem é complementada pelos estudos de Deepa Narayan, que privilegia a visão dos próprios pobres sobre "o que é ser pobre". A fim de situar o leitor sobre as abordagens anteriores de pobreza, procurou-se apresentar uma breve descrição desse conceito e como ele evoluiu com o passar do tempo: o enfoque de sobrevivência, a concepção de necessidades básicas, a idéia de privação relativa e a tese denominada "Consenso de Washington". Em suma, por meio de uma resenha simplificada das principais abordagens e concepções da pobreza, complementadas pelos trabalhos de Sen e Narayan, objetivou-se ampliar a discussão e as informações disponíveis sobre a pobreza como um fenômeno multidimensional.

\section{ABSTRACT}

The primary purpose of this article is to further promote academic discussion concerning poverty. It also draws attention in today's academic environment, to the widely spreading 'capacity deprivation approach', developed by Amartya Sen. Such approach can be complemented by the surveys of Deepa Narayan which focus on the poor's view of poverty. It also affords the reader the benefit of understanding historical poverty perceptions and their evolution over time: the survival approach, the basic needs theory, the relative deprivation idea and the "Consensus of Washington" theory. In summary, the article aims to heighten awareness, expand discussion and make available information about poverty as a multidimensional phenomenon by means of a simplified summary of poverty approaches, complemented by the work of Sen and Narayan.

\section{PALAVRAS-CHAVE}

Pobreza, privação de capacidades, ouvir, vozes dos pobres, multidimensional.

\section{KEY WORDS}

Poverty, capacity deprivation, hear, voices of the poor, multidimensional. 


\section{INTRODUÇÃO}

O objetivo deste artigo é conceituar o fenômeno da pobreza à luz das diferentes abordagens históricas existentes, complementadas pelas visões mais recentes de Amartya Sen (1999) e Deepa Narayan (2000). Tais autores foram escolhidos em razão do lugar de destaque que ocupam na discussão do tema, junto à comunidade acadêmica internacional e às organizações internacionais de desenvolvimento.

Na primeira parte do artigo serão descritas as abordagens do fenômeno da pobreza e as concepções de pobreza desenvolvidas ao longo do século XX. Assim, inicialmente, serão descritas as categorias nas quais se enquadram os conceitos de pobreza: pobreza como juízo de valor, pobreza relativa, pobreza absoluta e pobreza relativa/absoluta. Posteriormente, serão descritas as três concepções principais sobre a pobreza desenvolvidas ao longo do século XX: a da sobrevivência, a das necessidades básicas e a da privação relativa. Na segunda parte se discutirá a visão de Sen sobre a pobreza e sua relação com o conceito de desenvolvimento. Na terceira parte deste artigo, será apresentada a expansão que Narayan faz da visão de Sen acerca da pobreza, a partir de uma série de pesquisas feitas junto a pobres de todo o mundo, sob o patrocínio do Banco Mundial, denominada APP - Avaliação Participativa sobre a Pobreza. Na conclusão, será feito um apanhado geral do artigo, enfatizando seu objetivo primeiro: ser uma singela contribuição para a discussão da pobreza como fenômeno multidimensional.

\section{O CONCEITO DE POBREZA E SUA EVOLUÇÃO}

Nesta seção serão discutidas as abordagens do fenômeno da pobreza e suas concepções desenvolvidas ao longo do século XX.

A definição desses conceitos torna-se importante nos estudos de pobreza por permitir uma visão mais clara e analítica do objeto de estudo. Ao compreender a complexidade do fenômeno, seus diferentes conceitos e formas de abordagem, torna-se possível conceber políticas públicas que busquem trazer soluções eficazes para o problema.

A conceituação de pobreza é algo extremamente complexo. Pode ser feita levando em conta algum "juízo de valor", em termos relativos ou absolutos. Pode ser estudada apenas do ponto de vista econômico ou incorporando aspectos não-econômicos à análise, sendo contextualizada de forma dependente ou não da estrutura sócio-política da sociedade, o que não será explorado neste texto.

A conceituação de pobreza é categorizada como "juízo de valor" quando se trata de uma visão subjetiva, abstrata, do indivíduo, acerca do que deveria ser um grau suficiente de satisfação de necessidades, ou do que deveria ser um nível de privação normalmente suportável. O indivíduo expressa sentimentos e receitas, de caráter basicamente normativo, do que deveriam ser os padrões contemporâneos da sociedade quanto à pobreza. Não leva em conta uma situação social concreta, objetivamente identificável, caracterizada pela falta de recursos. Desse modo, tal enfoque não esconde sua fragilidade, embora seja bastante óbvio que mesmo uma conceituação objetiva da pobreza não se furta à presença de algum juízo de valor.

A percepção da pobreza como conceito relativo é uma abordagem de cunho macroeconômico, assim como o conceito de pobreza absoluta. A pobreza relativa tem relação direta com a desigualdade na distribuição de renda. É explicitada segundo o padrão de vida vigente na sociedade que define como pobres as pessoas situadas na camada inferior da distribuição de renda, quando comparadas àquelas 
melhor posicionadas. O conceito de pobreza relativa é descrito como aquela situação em que o indivíduo, quando comparado a outros, tem menos de algum atributo desejado, seja renda, sejam condições favoráveis de emprego ou poder. Uma linha de pobreza relativa pode ser definida, por exemplo, calculando a renda per capita de parte da população. Essa conceituação, por outro lado, torna-se incompleta ao não deixar margem para uma noção de destituição absoluta, requisito básico para a conceituação de pobreza. Também acaba gerando ambigüidade no uso indiferente dos termos pobreza e desigualdade que, na verdade, não são sinônimos.

O enfoque absoluto na conceituação da pobreza se observa quando da fixação de padrões para o nível mínimo ou suficiente de necessidades, conhecido como linha ou limite da pobreza, determinando a percentagem da população que se encontra abaixo desse nível. Esse padrão de vida mínimo, apresentado sob diferentes aspectos, sejam nutricionais, de moradia ou de vestuário, é normalmente avaliado segundo preços relevantes, calculando a renda necessária para custeá-los. Para o estabelecimento dos limites de pobreza utilizam-se diferentes enfoques, quer sejam o biológico, o das necessidades básicas ou o dos salários mínimos. O enfoque biológico define a linha de pobreza a partir dos requisitos nutricionais mínimos da dieta alimentar, definindo o valor aproximado para a renda a ser gasta para o atendimento desses requisitos. Por básicas entendem-se necessidades como alimentação, moradia, vestuário e serviços essenciais: água potável, saneamento, transporte público, serviços médicos e escolas. Já o enfoque dos salários mínimos lida com a idéia de que exista um salário mínimo oficial que deve ser uma boa aproximação do montante em dinheiro necessário para o nível de vida mínimo.

O enfoque da pobreza relativa/absoluta leva em conta que a abordagem relativa não estabelece uma linha acima da qual a pobreza deixaria de existir. Busca-se sanar este problema agregando a esta abordagem uma outra, de cunho absoluto. Por exemplo: ao calcular a renda per capita de parcelas da população (abordagem relativa), fixa-se a linha de pobreza na metade da renda per capita média do país (abordagem absoluta). De toda forma, a arbitrariedade continua presente nesse procedimento, posto que não existe uma razão a priori na qual uma determinada proporção estatística sumária possa ser considerada como linha da pobreza.

A partir das diferentes abordagens sobre o conceito de pobreza acima descritas, três concepções foram desenvolvidas no decorrer do século XX: sobrevivência, necessidades básicas e privação relativa.

O enfoque de sobrevivência, o mais restritivo, predominou nos séculos XIX e XX, até a década de 50. Teve origem no trabalho de nutricionistas inglesas apontando que a renda dos mais pobres não era suficiente para a manutenção do rendimento físico do indivíduo. Essa concepção foi adotada na Inglaterra e exerceu grande influência em toda a Europa, sendo usada mais tarde pelo Banco Internacional para a Reconstrução e o Desenvolvimento (BIRD). Com a utilização de medidas estatísticas, formulou-se o primeiro modelo de proteção social para o Estado de bem-estar, fundamentando políticas nacionais de assistência e alguns programas. Seus verdadeiros objetivos seriam limitar as demandas por reformas sociais e, ao mesmo tempo, preservar a ênfase no individualismo compatível com o ideário liberal. A maior crítica que esse enfoque sofreu foi que, com ele, justificavam-se baixos índices de assistência: bastava manter os indivíduos no nível de sobrevivência.

Num segundo momento, a partir de 1970, a pobreza tinha a conotação de necessidades básicas, colocando novas exigências, como serviços de água potável, saneamento básico, saúde, educação e cultura. Configurou-se o enfoque das necessidades básicas, apontando certas exigências de consumo básico de uma família. Essa concepção passou a ser adotada pelos órgãos internacionais, sobretudo por 
aqueles que integram a Organização das Nações Unidas (ONU), representando uma ampliação da concepção de sobrevivência física pura e simples.

A partir de 1980, a pobreza passou a ser entendida como privação relativa, dando ao conceito um enfoque mais abrangente e rigoroso, buscando uma formulação científica e comparações entre estudos internacionais, enfatizando o aspecto social. Dessa forma, sair da linha de pobreza significava obter: um regime alimentar adequado, um certo nível de conforto, o desenvolvimento de papéis e de comportamentos socialmente adequados. Ao mesmo tempo, porém, contrapondo-se a este conceito, floresceu a tese, muito apreciada pelas instituições multilaterais de crédito sediadas na capital norteamericana, de que, com o bom funcionamento dos mercados, as economias se tornariam prósperas, e a riqueza gerada acabaria por beneficiar os pobres. Essa tese ficou conhecida como "Consenso de Washington".

O enfoque da privação relativa evoluiu tendo como um de seus principais formuladores o indiano Amartya Sen, ganhador do prêmio Nobel de Economia (1999). Seu conceito introduz variáveis mais amplas, chamando a atenção para o fato de que as pessoas podem sofrer privações em diversas esferas da vida. Ser pobre não implica somente privação material. As privações sofridas determinarão o posicionamento dos cidadãos nas outras esferas.

Essa abordagem, apesar de ser mais sofisticada e abrangente, apresenta mais dificuldades de utilização, dada a necessidade de definir a extensão e a severidade da não participação das pessoas que sofrem privação de recursos.

Nas duas seções seguintes, serão abordados o conceito de pobreza desenvolvido por Amartya Sen e a extensão desse conceito feita por Deepa Narayan.

\section{A POBREZA COMO PRIVAÇÃO DE CAPACIDADES}

Segundo Amartya Sen (1999), a pobreza pode ser definida como uma privação das capacidades básicas de um indivíduo e não apenas como uma renda inferior a um patamar pré-estabelecido.

Por "capacidade" entendem-se as combinações alternativas de funcionamentos de possível realização. Portanto, a capacidade é um tipo de liberdade: a liberdade substantiva de realizar combinações alternativas de funcionamentos ou a liberdade para ter estilos de vida diversos. Por exemplo, uma pessoa abastada que faz jejum por sua livre e espontânea vontade pode ter a mesma realização de funcionamento que uma pessoa pobre forçada a passar fome extrema. Porém a primeira pessoa possui um "conjunto capacitário" diferente do da segunda. A primeira pode escolher comer bem e ser bem nutrida de um modo impossível para a segunda. (SEN, 1999)

Os funcionamentos são definidos como o que uma pessoa pode considerar valioso fazer ou ter. Os funcionamentos podem variar dos elementares, como ser adequadamente nutrido e livre de doenças evitáveis, a atividades ou estados pessoais muito complexos, como poder participar da vida da comunidade e ter respeito próprio.

Assim, a privação de capacidades elementares pode refletir-se em morte prematura, subnutrição considerável (especialmente de crianças), morbidez persistente, analfabetismo e outras deficiências. Essa definição não despreza o fato de a pobreza também ser caracterizada como uma renda inferior a um patamar pré-estabelecido, pois uma renda baixa pode ser a razão primeira da privação de capacidades de uma pessoa. 
A relação entre renda e capacidade é demasiadamente afetada pela idade da pessoa (necessidades específicas dos idosos e muito jovens), pelos papéis sexuais e sociais (por exemplo, as responsabilidades da maternidade e também as obrigações familiares determinadas culturalmente), pela localização (por exemplo, propensão a inundações ou secas, ou insegurança e violência em alguns bairros pobres e muito populosos), pelas condições epidemiológicas (por exemplo, doenças endêmicas em uma região) e por outras variações sobre as quais uma pessoa pode não ter controle ou ter um controle apenas limitado.

Desvantagens, como idade, incapacidade ou doença, reduzem o potencial do indivíduo para auferir renda. Além disso, também tornam mais difícil converter renda em capacidade, já que uma pessoa mais velha, mais incapacitada ou mais gravemente enferma pode necessitar de mais renda (para assistência, próteses, tratamentos) para obter os mesmos funcionamentos. Isso implica que a pobreza real (no que se refere à privação de capacidades) pode ser mais intensa do que possa parecer no espaço da renda.

A distribuição de renda dentro da família acarreta complicações adicionais na abordagem da pobreza baseada na renda. Se a renda familiar é usada desproporcionalmente no interesse de alguns membros da família em detrimento de outros (por exemplo, se existe uma preferência generalizada pelos meninos na alocação dos recursos da família), o grau de privação dos membros negligenciados (no exemplo em questão, as meninas) pode não ser evidenciado pela renda familiar. A privação das meninas é mais facilmente constatada quando se verifica a privação de capacidades (mortalidade, morbidez, subnutrição, negligência médica, mais elevadas) em oposição ao uso da análise baseada na renda.

O que a perspectiva da capacidade faz na análise da pobreza é melhorar o entendimento da natureza e das causas da pobreza e privação desviando a atenção principal dos meios (renda) para os fins que as pessoas têm razão para buscar e para as liberdades de poder alcançar esses fins.

Ambas as perspectivas, a noção de pobreza como inadequação de capacidade e a noção de pobreza como baixo nível de renda, estão vinculadas, uma vez que a renda é um meio fundamental na obtenção de capacidade. E, quanto mais capacidades, maior o potencial produtivo de uma pessoa e, conseqüentemente, maior a chance de se obter uma renda mais elevada. Note que uma renda mais elevada não significa necessariamente capacidades maiores.

Essa relação, portanto, é importante na eliminação da pobreza de renda. Com uma educação básica e serviços de saúde melhores há um aumento no potencial do indivíduo de auferir renda e de, assim, livrar-se da pobreza medida pela renda. Quanto mais inclusivo for o alcance da educação básica e dos serviços de saúde, maior será a probabilidade de que mesmo os potencialmente pobres tenham uma chance maior de superar a penúria.

Segundo Sen, é importante ter em mente que a redução da pobreza de renda não pode ser o único objetivo de políticas de combate à pobreza. É perigoso ver a pobreza segundo a perspectiva limitada da privação de renda e a partir daí justificar investimentos em educação, serviços de saúde, etc., com o argumento de que são bons meios para a redução da pobreza. Isso seria confundir os fins com os meios. A pobreza deve ser entendida como a privação da vida que as pessoas realmente podem levar e das liberdades que elas realmente têm. A expansão das capacidades humanas enquadra-se justamente nesse ponto. Não se pode esquecer que o aumento das capacidades humanas tende a caminhar junto com a expansão das produtividades e do poder de auferir renda. Um aumento de capacidades ajuda direta e indiretamente a enriquecer a vida humana e a tornar as privações humanas mais raras e menos crônicas. As relações instrumentais, por mais importantes que sejam, não podem substituir a necessidade de uma compreensão básica da natureza e das características da pobreza. 


\section{DESENVOLVIMENTO COMO EXPANSÃO DAS LIBERDADES}

Para Sen, o conceito de privação relativa que é atribuído à pobreza relaciona-se diretamente com sua visão de desenvolvimento.

Para ele, o desenvolvimento pode ser visto como um processo de expansão das liberdades das pessoas. Ver o desenvolvimento como expansão de liberdades substantivas chama atenção para os fins em vez de restringi-la para os meios que desempenham um papel importante no processo. Nessa abordagem, a expansão da liberdade é considerada o fim primordial (papel constitutivo) e o principal meio do desenvolvimento (papel instrumental). O papel constitutivo relaciona-se com a importância da liberdade substantiva no enriquecimento da vida humana. As liberdades substantivas incluem capacidades elementares como, por exemplo, ter condições de evitar a fome, a subnutrição, a morbidez e a morte prematura, além de saber ler e fazer cálculos aritméticos, ter participação política e liberdade de expressão, etc.

O desenvolvimento supõe que se removam as principais fontes de privação de liberdade: pobreza e tirania, carência de oportunidades econômicas e destituição social sistemática, negligência dos serviços públicos e intolerância ou interferência excessiva de Estados repressivos.

A condição de agente livre e sustentável emerge como um pilar fundamental do desenvolvimento. Além de ser uma parte constitutiva do desenvolvimento, contribui para fortalecer outros tipos de condições de agentes livres (alguém que age e ocasiona mudanças e cujas realizações podem ser julgadas de acordo com os seus valores e objetivos).

As diferentes formas de liberdade relacionam-se entre si fortalecendo umas às outras. Liberdades políticas (na forma de liberdade de expressão e eleições livres) ajudam a promover a segurança econômica. Oportunidades sociais (na forma de serviços de educação e saúde) facilitam a participação econômica. Facilidades econômicas (na forma de oportunidades de participação no comércio e na produção) podem ajudar a gerar renda individual, além de recursos públicos para os serviços sociais.

O processo de desenvolvimento centrado na liberdade é em grande medida uma visão orientada para o agente. Com oportunidades sociais adequadas, os indivíduos podem efetivamente arquitetar o seu próprio destino.

As liberdades dos indivíduos são os elementos constitutivos básicos do desenvolvimento apontado por Sen. Assim, dá-se atenção para a expansão das capacidades das pessoas de levar o tipo de vida que elas valorizam. Essas capacidades podem ser aumentadas por intermédio das políticas públicas e também a direção da política pública pode ser influenciada pelo uso efetivo das capacidades participativas do povo.

São cinco os tipos de liberdade instrumental, analisados por Sen: liberdades políticas, facilidades econômicas, oportunidades sociais, garantias de transparência e segurança protetora.

As liberdades políticas referem-se às oportunidades que as pessoas têm para determinar quem deve governar e com base em quais princípios, além de incluírem a possibilidade de fiscalizar e criticar as autoridades, de ter liberdade de expressão política e uma imprensa sem censura, de ter a liberdade de escolher entre diferentes partidos políticos, etc. Incluem os direitos políticos associados às democracias no sentido mais abrangente: diálogo político, crítica, direito ao voto e seleção participativa dos legisladores e representantes do Executivo. 
As facilidades econômicas são as oportunidades que os indivíduos têm para utilizar recursos econômicos com propósitos de consumo, produção ou troca. Os intitulamentos (conjunto de pacotes alternativos de bens que podem ser adquiridos mediante o uso de vários canais legais de aquisição/dotações) econômicos que uma pessoa tem dependerão dos seus recursos disponíveis, bem como das condições de troca, como os preços relativos e o funcionamento dos mercados. À medida que o processo de desenvolvimento econômico aumenta a renda e a riqueza de um país, elas se refletem no correspondente aumento de intitulamentos econômicos da população.

Oportunidades sociais são as disposições que a sociedade estabelece nas áreas de educação, saúde, etc, as quais influenciam a liberdade substantiva de o indivíduo viver melhor. Essas facilidades são importantes não só para a condução da vida privada (como, por exemplo, levar uma vida saudável, livrando-se da morbidez evitável e da morte prematura), mas também para uma participação mais efetiva em atividades econômicas e políticas.

Nas interações sociais, os indivíduos lidam uns com os outros, com alguma presunção básica de confiança. As garantias de transparência referem-se às necessidades de sinceridade que as pessoas podem esperar: a liberdade de lidar uns com os outros sob garantias de transparência e clareza. Quando essa confiança é gravemente violada, as vidas de numerosas pessoas podem ser afetadas negativamente. As garantias de transparência podem, portanto, ser uma categoria importante de liberdade instrumental. Essas garantias têm um claro papel instrumental como inibidoras da corrupção, da irresponsabilidade financeira e de transações ilícitas.

Finalmente, não importando como opera um sistema econômico, algumas pessoas podem encontrar-se no limiar da vulnerabilidade e sucumbir a uma grande privação em conseqüência de mudanças materiais que afetem adversamente suas vidas. A segurança protetora é necessária para proporcionar uma rede de segurança social, impedindo que a população afetada seja reduzida à miséria absoluta e, em alguns casos, até mesmo à fome e à morte. A esfera da segurança protetora inclui disposições institucionais fixas, como benefícios aos desempregados e suplementos de renda regulamentares para os indigentes, bem como, por exemplo, a distribuição de alimentos em crises de fome coletiva ou empregos públicos de emergência para gerar renda para os necessitados.

Essas liberdades instrumentais alimentam-se umas às outras, reforçando-se. Assim, o crescimento econômico tem de ser julgado não apenas pelo aumento de rendas privadas, mas também pela expansão de serviços sociais que ele pode estimular. De maneira similar, a criação de oportunidades sociais, por meio de serviços como educação pública, saúde e uma imprensa livre, pode contribuir para o desenvolvimento econômico e para uma redução significativa das taxas de mortalidade. A educação básica (em especial a alfabetização e escolaridade das mulheres) pode influenciar as taxas de fecundidade.

\section{NARAYAN: OUVINDO O QUE OS POBRES TÊM A DIZER}

Deepa Narayan (2000) procura expandir o conceito de pobreza apresentado por Sen, a partir das conclusões obtidas em estudos desenvolvidos, desde 1993, pelo Banco Mundial. Este passou a realizar Avaliações Participativas sobre a Pobreza (APP's) como forma de incorporar às suas análises uma dimensão humana e social, entrevistando populações desprovidas, em vários países do mundo, sobre suas opiniões acerca do que é ser pobre. Ninguém melhor do que os próprios pobres para falar sobre sua situação. Sua disposição para melhorar de condição depende da forma como encaram as oportunidades, os riscos e as limitações que se lhe apresentam uma vez que somente eles podem mudar sua situação. Grande parte do que a sociedade faz para ajudá-los terá validade na medida de sua 
aceitação. O investimento em uma escola, hospital ou conjunto habitacional será inútil se não houver concordância dos beneficiários. Portanto, as estratégias de redução de pobreza só serão eficazes e sustentáveis se corresponderem a um conhecimento sistemático das percepções dos pobres.

As APP's concentraram-se, basicamente, em como os pobres percebem as várias manifestações da pobreza (renda baixa, falta de alimentos, propensão a doenças), em suas principais causas e fatores limitantes de suas oportunidades (por exemplo, pouco acesso a bens como terras e créditos; fatores geofísicos que causam isolamento e discriminação de sexo, etnia, classe ou religião) e em como eles viam os serviços públicos (por exemplo, centros de saúde, escolas, programas de planejamento familiar ou de extensão agrícola). Assim, ao utilizar esse enfoque, tem-se uma perspectiva multicultural da pobreza, uma perspectiva que perpassa a renda e os gastos em educação e saúde, uma perspectiva que considera a capacidade de os pobres serem ouvidos e de ganharem poder como agentes de seu próprio destino.

As condições de vida dos pobres, segundo eles mesmos são, geralmente, críticas e negativas. Uma parte considerável da população pobre não recebe nenhum apoio institucional que não seja o da sua própria família. Além disso, a qualidade do atendimento prestado nos centros de saúde pública é objeto de queixas constantes. A educação, segundo os pobres, é avaliada pelo custo-benefício. Além disso, foram destacados, como problemas graves, a crise econômica e a violência familiar ocasionada pelo abuso do álcool e das drogas.

As principais conclusões dessas pesquisas, são discriminadas abaixo:

Muitos fatores convergem para tornar a pobreza um fenômeno multidimensional inter-relacionado. Isso significa que a pobreza e suas causas variam segundo a idade, gênero, cultura e outros contextos sociais e econômicos.

A pobreza é definida, geralmente, como a falta do que é necessário para o bem-estar material especialmente alimentos, moradia, terra e outros ativos. Em outras palavras, a pobreza é a falta de recursos múltiplos que leva à fome e à privação física.

Há o aspecto psicológico da pobreza. Os pobres têm consciência de sua falta de voz, poder e independência que os sujeita à exploração. A pobreza os deixa mais vulneráveis à humilhação e ao tratamento desumano pelos agentes públicos e privados a quem, freqüentemente, solicitam ajuda. Os pobres também falam sobre a dor causada pela inevitável ruptura com as normas sociais e sua incapacidade de manter sua identidade cultural por meio da participação em tradições, festivais e rituais. A incapacidade de participar na vida comunitária leva a uma ruptura das relações sociais.

A ausência de infra-estrutura básica (rodovias nas áreas rurais, transporte e água) emerge como uma preocupação importante. Também a falta de energia elétrica é valorizada em áreas onde o frio é severo.

A doença também é temida por lançar as famílias à pobreza. Ela pressupõe falta de cuidados com a saúde, custos elevados com tratamentos médicos e a perda da vida pela doença. Apesar de a alfabetização ser vista como importante, a escolaridade recebeu opiniões diversas, ora extremamente valorizada, ora irrelevante para a condução da vida dos pobres.

Os pobres valorizam mais os ativos do que a renda e associam sua falta de ativos físicos, humanos, sociais e ambientais à sua vulnerabilidade e exposição ao risco. 
Como já mencionado acima, os pobres explicam o seu bem-estar relacionando-o a cinco dimensões: bem-estar material, bem-estar físico, segurança protetora, liberdade de escolha e de ação e boas relações sociais.

Quanto ao bem-estar material, os pobres sempre mencionam a falta de comida, abrigo e vestimenta, moradia precária e fontes de subsistência incertas. Também a disponibilidade de alimentos ao longo do ano foi mencionada, assim como a posse de ativos. Nas áreas rurais, essas demandas tomam a forma de terras, juntamente com a posse de ativos que permitam o cultivo e uma boa colheita. Nas áreas urbanas, foi mencionado o capital para iniciar um negócio, o acesso ao crédito e a dependência do trabalho como um sinônimo para não morrer de fome. Aqueles que moram em países que passaram por crises econômicas severas e de reestruturação e que passaram fome sentem-se orgulhosos em mendigar e não sentem vergonha alguma em roubar.

No que tange ao bem-estar físico, são de grande importância para os pobres a boa saúde, a força e a aparência. O corpo é o principal ativo das pessoas pobres e ele não está segurado. Se ele se deteriora, a fome e a pobreza se seguem. As péssimas condições de vida aliadas à pobreza material tornam uma pessoa extremamente vulnerável à doença pela fraqueza, à deficiência física permanente ou à morte por doença ou acidente. A restrição alimentar e a doença não só causam dor, mas enfraquecem e desvalorizam o "ativo". As pessoas pobres estão mais sujeitas a ficar doentes por um período maior de tempo e têm menos condições de arcar com os custos de um tratamento, quando comparadas aos mais ricos. As mulheres, pelo fato de estar, cada vez mais, com uma sobrecarga maior devido aos seus múltiplos papéis (mãe, mulher, dona-de-casa, assalariada), são as mais suscetíveis à exaustão completa. Portanto, a doença pode levar uma família imediatamente à pobreza.

No aspecto da segurança, muitas pessoas a descrevem como paz de espírito e confiança na sobrevivência. A sobrevivência, não só como subsistência mas também como sobrevivência física, diante da crescente corrupção, crime, violência, falta de proteção da polícia e ausência de justiça, sobrevivência a desastres naturais e a incertezas do clima e das estações. A lei e o acesso à justiça são vistos como aspectos cruciais ao bem-estar.

A insegurança também está relacionada ao sentimento de vulnerabilidade. Relaciona-se ao mundo externo, ao indivíduo e à família: a exposição a choques, a situações de estresse e a riscos que aumentam a imprevisibilidade e a instabilidade. Ela também é a experiência da preocupação e do medo. Mesmo onde a pobreza diminuiu, a maioria das pessoas pobres diz que a vida tornou-se instável e incerta, particularmente como resultado do crime crescente, da violência e da corrupção.

Bem-estar para muitas pessoas significa liberdade de escolha e de ação e o poder para controlar sua própria vida. Significa também poder evitar a exploração, a agressão e qualquer tipo de tratamento humilhante, constantemente imposto aos pobres pelos ricos ou pelos mais poderosos na sociedade. Também inclui a capacidade na aquisição de habilidades, educação, empréstimos, informação, serviços e recursos, de viver em lugares bons, de suportar choques e estresse repentinos e sazonais e de não cair novamente na pobreza absoluta. $\mathrm{O}$ bem-estar freqüentemente se relaciona à responsabilidade moral, à liberdade de escolha e ação e à capacidade de ajudar aqueles que precisam. Resumidamente, os pobres mencionam quatro problemas crônicos e sistêmicos que afetam sua liberdade de escolha e de ação adversamente em quase todos os lugares: corrupção, violência, subsistência insegura e falta de poder.

A falta de poder mencionada é explicada como a incapacidade de controlar o que acontece ao indivíduo devido à pobreza. Os pobres são forçados a trocar uma coisa ruim por outra, não têm opção melhor. Suas vozes são ouvidas raramente e, algumas vezes, até silenciadas. Sua falta de organização acaba 
impedindo que eles enfrentem as autoridades quando se observam submetidos a práticas ilegais. Além disso, podem viver em áreas extremamente pobres, caracterizadas pelo isolamento e distância.

O bem-estar social pode ser definido como bons relacionamentos na família e na comunidade. Ter condições de cuidar, educar, casar e dar um meio de vida às crianças foi mencionado várias vezes. $\mathrm{O}$ bem-estar social inclui o respeito social e o fazer parte de uma comunidade. O estigma da pobreza foi um tema recorrente, e os participantes freqüentemente mencionaram a vergonha de pedir ajuda e de aceitar a caridade alheia. Muitos falaram da humilhação trazida pela pobreza quando impedidos de seguir as tradições e costumes de sua cultura. Também falaram de sua incapacidade de trocar presentes e como, em conseqüência, eles ficaram de fora de celebrações, casamentos e festividades. A solidão, a alienação e os desentendimentos foram descritos como uma fonte de grande estresse psicológico. Os pobres também reclamam de oportunidades negadas e de tratamento humilhante por parte de guardas de supermercados, médicos, enfermeiras, professores de escolas e comerciantes.

Assim, uma definição resumida do conceito de pobreza dada pelos pobres é dada a seguir:

"Pobreza é fome, é falta de abrigo. Pobreza é estar doente e não poder ir ao médico. Pobreza é não poder ir à escola e não saber ler. Pobreza é não ter emprego, é temer o futuro, é viver um dia de cada vez. Pobreza é perder o seu filho para uma doença trazida pela água não tratada. Pobreza é falta de poder, falta de representação e liberdade".

Resumindo, Narayan entende que as estratégias de redução da pobreza, para ser eficazes e sustentáveis, devem refletir um conhecimento sistemático das percepções dos pobres.

\section{CONCLUSÃO}

Foi feita uma introdução acerca das principais abordagens do conceito de pobreza e das diferentes concepções desenvolvidas no século passado - sobrevivência, necessidades básicas e privação relativa. Essa conceituação e a descrição de abordagens tiveram por objetivo descrever as principais correntes que surgiram para explicar o fenômeno da pobreza.

A fim de complementar essa seção, foi feita uma comparação entre as visões de dois expoentes mundiais no assunto: Amartya Sen e Deepa Narayan. Ambos desenvolveram trabalhos teóricos para o Banco Mundial e para a comunidade acadêmica internacional acerca da pobreza. Seus estudos até serviram de base para o desenvolvimento de alguns programas públicos nessa área. $\mathrm{O}$ artigo discutiu brevemente a abordagem de privação relativa desenvolvida por Sen. Complementando sua abordagem, expandiu-se seu conceito de pobreza com o trabalho de Narayan, em que ela destaca a importância de ouvir o que os pobres têm a dizer sobre sua condição.

Através dos vários tópicos desenvolvidos no artigo conclui-se que a pobreza é um fenômeno multidimensional em que há a falta do que é necessário para o bem-estar material. Associa-se a esse conceito a falta de voz, poder e independência dos pobres que os sujeita à exploração; à propensão à doença; à falta de infra-estrutura básica, à falta de ativos físicos, humanos, sociais e ambientais e à maior vulnerabilidade e exposição ao risco.

Finalmente, o presente artigo visa tornar-se mais uma contribuição para os estudiosos da pobreza e para aqueles que focam o pobre como agente de seu próprio destino. Por meio de uma resenha simplificada das principais abordagens e concepções da pobreza, complementadas pelos trabalhos de Amartya Sen e Deepa Narayan, buscou-se ampliar a discussão e as informações disponíveis sobre o tema. 


\section{Artigo recebido em 29.06.2001. Aprovado em 11.06.2002}

\section{BIBLIOGRAFIA}

JAMUR, Marilena et al. A noção da pobreza frente às desigualdades sociais. in CAMAROTTI, Ilka; SPINK, Peter Kevin (Coord.). Estratégias locais para redução da Pobreza: construindo a cidadania. São Paulo: Escola de Administração de Empresas de São Paulo da Fundação Getulio Vargas, 2000, p. 18-21. Oficina

KOHUT, John et al. A nova face da pobreza. O Correio da Unesco, Brasil, Ano 27, n. 5, p. 17-19, Maio 1999.

NARAYAN, D. Voices of the poor - Can anyone hear us? Washington, D.C.: The World Bank, Oxford University Press, 2000.

ROMÃO, Maurício E.C. Considerações sobre o conceito de pobreza. Revista Brasileira de Economia, Rio de Janeiro, v. 36, n. 4, p. 355-370, Out./Dez. 1982.

SALMEN, Lawrence. Ouvir os pobres. Finanças \& Desenvolvimento, Washington, D.C., v. 14, n. 4, Dezembro 1994.

SEN, Amartya K. Desenvolvimento como Liberdade. São Paulo: Companhia das Letras, 2000. 